\title{
Quantum Wire Arrays in Compositionally Modulated InAs/AlAs Superlattices
}

\author{
D. M. Follstaedt, J. L. Reno, and S. R. Lee
}

Sandia National Laboratories, Physical \& Chemical Sciences Center, Albuquerque, NM 87185-1056

Compound semiconductor alloys have limited miscibility, which can lead to composition segregation during growth. This effect produces periodic lateral composition modulation in epitaxial InAsAlAs [1] and other alloys [2]. Intense modulation is found in vertical (InAs $h_{h} /(\mathrm{AlAs})_{\mathrm{m}}$ superlattices $(\mathrm{n} \approx \mathrm{m}$ $\approx 2$ ) grown by molecular beam epitaxy [3]. Growth on (001) InP substrates leads to two modulation directions with only short InAs-enriched regions $(\sim 0.1 \mu \mathrm{m})$ [4]. Superlattices with global-average compositions slightly rich in InAs $(n>m)$ have modulations $\sim 8^{\circ}$ from the in-plane $\langle 100\rangle$ directions. Growth on substrates miscut $2^{\circ}$ toward (100) selects the modulation near [100], resulting in vertical sheets enriched in InAs and extending nearly parallel to [010] with lengths approaching $\sim 1 \mu \mathrm{m}$.

We examined such a superlattice but with InAlAs random-alloy layers placed between sections of superlattice modulated nearly along [100]. A lattice-matched $100 \mathrm{~nm}$-thick $\operatorname{In}_{0.52} \mathrm{Al}_{0.48} \mathrm{As}$ buffer alloy was grown on the miscut InP, followed by superlattice sections, eadh with 10 vertical periods of $\mathrm{n}=1.90, \mathrm{~m}=1.52$. Ten such sections were grown with $7.5 \mathrm{~nm}$-thick InAlAs random alloy layers placed between them. The growth temperature rose a few degrees above $535^{\circ} \mathrm{C}$, determined by an optical pyrometer at the initiation of growth. Figure 1 is a cross-section image obtained with (002) dark-field conditions for sensitivity to composition variations [3]. Composition modulation appears as light/dark variations that begin in the first superlattice section and reach a steady-state intensity by about the fourth section. The average lateral periodicity is $30 \mathrm{~nm}$. The bright InAs-rich wires stack vertically above those below. Atomic steps on the miscut growth surface bunch together at some AlAs-rich regions between wires; the $2.7 \mathrm{~nm}$ drop indicated near the center of the image corresponds to $\approx 9$ monoatomic steps. Such drops probably relate to how one modulation direction is selected. Slight contrast is seen in the alloy layers, especially above the stack; this may indicate some ompositional variation induced by the modulated superlattice, or may be due to lattice strain. Figure 2 is a plan-view, (200) dark-field image showing the in-plane organization of the wire stacks. Wires up to $\sim 1 \mu \mathrm{m}$ long are found nearly parallel to [010], with the modulation direction $\sim 8^{\circ}$ from [100] toward [110] as before. These wires are of interest because their small cross section induces quantum confinement of electronic carriers, and they exhibit polarized optical emission and absorption [5].

Sandia is a multiprogram laboratory operated by Sandia Corporation, a Lockheed Martin Company, for the United States Department of Energy. This work supported by Division of Materials Sciences, Office of Basic Energy Science under contract DE-AC04-94A185000.

[1] J. Mirecki Millunchick, R. D. Twesten, S. R. Lee, D. M. Follstaedt, E. D. Jones, S. P. Ahrenkiel, Y. Zhang, H. M. Cheong and A. Mascarenhas, MRS Bulletin 22, No. 7 (1997) 38.

[2] K. C. Hsieh, J. N. Baillargeon and K. Y. Cheng, Appl. Phys. Lett. 57 (1990) 224.

[3] R. D. Twesten, D. M. Follstaedt, S. R. Lee, E. D. Jones, J. L. Reno, J.Mirecki Millunchick, A. Norman, P. Ahrenkiel and A. Mascarenhas, Phys. Rev. B 60 (1999) 13619.

[4] A.G. Norman, S. Ahrenkiel, H. Moutinho, M. Al-Jassim, A. Mascarenhas, J. Mirecki Millunchick, S.R. Lee, R.D. Twesten, D.M. Follstaedt, J.L. Reno and E.D. Jones, Appl. Phys. Lett. 73 (1998) 1844. [5] S. Francoeur, A. G. Norman, A. Mascarenhas, E. D. Jones, J. L Reno, S. R. Lee and D. M. Follstaedt, submitted to Applied Physics Letters. 
FIG 1. [010] cross-sectional image of quantum wires obtained using (200) darkfield conditions at $200 \mathrm{kV}$. Image is oriented with [001] vertical and the buffer layer tilted $2^{\circ}$ below horizontal. Composition modulation in superlattice sections appears as bright/dark/bright.... contrast. InAs-rich wires (bright) are typically about $10 \mathrm{~nm} \times 15 \mathrm{~nm}$ in crosssection. Note that the wires stack vertically in columns. Steps on the growth surface bunch together in the AlAsrich regions between the wires, such as near the center where adjacent wires have a vertical drop between them, illustrated with the horizontal bar. Weak contrast is seen in the InAlAs alloy layers between sections and above the stack. (specimen EA0674).

FIG 2. [001] plan-view image of quantum wires obtained with (200) dark-field conditions at $200 \mathrm{kV}$. InAs-rich wires appear bright, and extend for lengths up to $\sim 1 \mu \mathrm{m}$. The average modulation direction (double arrow) is $8^{\circ}$ from [100] toward [110]. In the varying pattern, some wires are cut off; others join adjacent ones. (specimen EA0674).
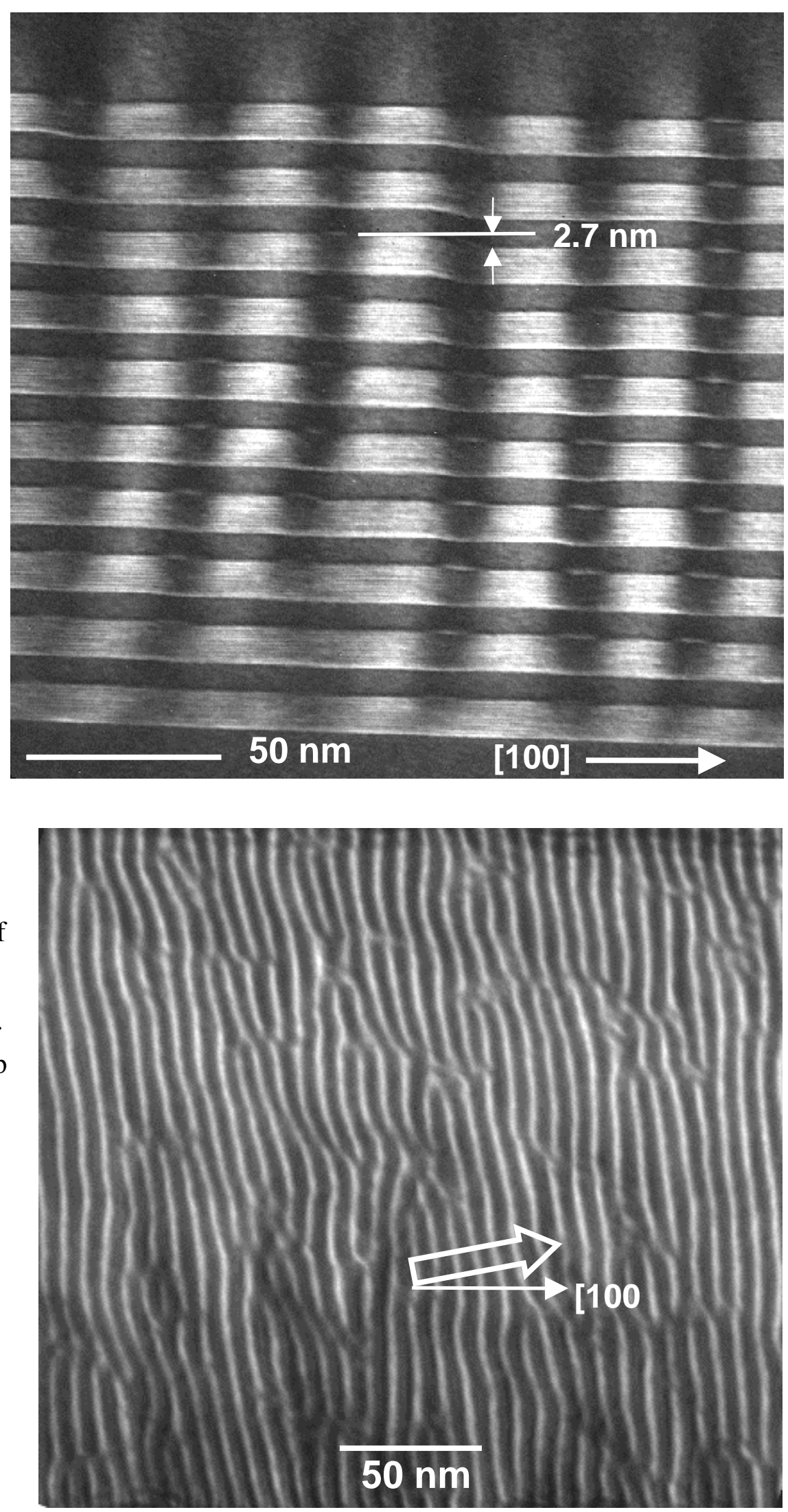